\title{
Autosomal Recessive Autism: Cure of the Major Autistic Features
}

\author{
Aamir Jalal Al Mosawi
}

Advisor in Pediatrics and Pediatric Psychiatry Children Teaching Hospital of Baghdad Medical CityHead, Iraq Headquarter of Copernicus Scientists International Panel Baghdad, Iraq.

Corresponding Author: Aamir Jalal Al Mosawi, Advisor in Pediatrics and Pediatric Psychiatry Children Teaching Hospital of Baghdad Medical City, Iraq.

Received date: September 22, 2021; Accepted date: December 23, 2021; Published date: January 01 , 2022

Citation: Aamir Jalal A, M. (2022). Autosomal Recessive Autism: Cure of the Major Autistic Features. International Journal of Clinical Case Reports and Reviews. 10(1); DOI:10.31579/2690-4861/177

Copyright: (02022 Aamir Jalal Al Mosawi, This is an open-access article distributed under the terms of the Creative Commons Attribution License, which permits unrestricted use, distribution, and reproduction in any medium, provided the original author and source are credited.

\begin{abstract}
Background: We have previously reported our extensive experiences with autism disorders and their treatments, and we showed the possibility of curing the major autistic features with a new therapeutic approach which included individualized courses of intramuscular cerebrolysin as the main therapy for the main autistic features. Our previously published experiences included observing the occurrence of atypical autism associated with evidence of mental retardation in four brothers from outside Baghdad, each two of them from two unrelated families. The four patients were treated based on our extensive published experiences with the pharmacological treatments of autism disorders; however, the follow-up and the outcome of treatments of these four children were not described in the previous publications. The aim of this paper is to report the cure of the major autistic features in 2 brothers with autosomal recessive autism.
\end{abstract}

Patients and methods: It was possible to follow the first two brothers for only few weeks and to see them after the first course of treatment, however, the second brothers were followed for more than one year, and it was possible to achieve cure of the main autistic features.

Results: After one short course, the first two brothers showed slight but noticeable improvement. The younger brother showed some reduction in autistic features as he developed rather an acceptable eye contact. However, the two brothers were still not responding to name and didn't say any word.

After, treatment, the second two brothers showed no autistic features, and experienced significant improvements in speech and cognitive functions. The older brother was not having autistic features after eighth months, and was obeying commands, but was still saying only few words. The younger brother joined primary school and was doing well apart from some behavioral problems especially running away from school and sometimes breaks things.

Conclusion: In this paper, cure of autism has been achieved in two boys with autosomal recessive disorder. However, cure of autism in older children has never been expected to totally normalizes them, as the patients have already lost several years of learning, social adaptation, and maturation of personality and behavior.

Keywords: autosomal; autism; autistic; intramuscular; cerebrolysin; trifluoperazine; prochloperazine

\section{Introduction}

Autistic disorders which are also called "Pervasive developmental disorders" are a very complex and heterogeneous group of disorders characterized by early impairments in social interaction and communication and behavioral problems which are clinically dominated by the main autistic feature which include poor or no eye contact, poor or no response to name, and poor or no speech development. However, patients with Asperger syndrome have good speech development. A child with acceptable eye contact and acceptable response to name can not receive the diagnosis of an autism disorder [1-10].
We have previously reported our extensive experiences with autism disorders and their treatment, and we showed the possibility of curing the major autistic features with a new therapeutic approach which included individualized courses of intramuscular cerebrolysin as the main therapy for the main autistic features. Courses of intramuscular cerebrolysin were individualized according to the age and severity of the illness, and with aim of improving social interactions including response to name, looking at faces, and eye contact. 
It was speculated that improvements in social interaction can contribute to improving other features of autism, especially verbal communication and speech.

Many patients with autism disorders need neuroleptics to control hyperactivity, anxiety and other abnormal behaviors. Trifluoperazine and prochloperazine were used frequently. Risperidone was also used in patients with severe disorder. Some patients also receive citicoline as an adjunctive therapy to improve speech development and cognitive functions, and piracetam can also be given to improve cognitive functions in atypical autism with mental retardation $[11,12,13]$.

Our previously published experiences included observing the occurrence of atypical autism associated with evidence of mental retardation in four brothers from outside Baghdad, each two of them from two unrelated families. The diagnosis of atypical autism was based on evidence of mental retardation as indicated by poor and late development of adaptive behaviors including bowel control and spoon feeding [12, 13]. The four patients were treated based on our extensive published experiences with the pharmacological treatments of autism disorders; however, the followup and the outcome of treatment of these four children were not described in the previous publications $[12,13]$.

The aim of this paper is to report the cure of the major autistic features in two brothers with autosomal recessive autism.

\section{Patients and methods}

It was possible to follow the first brothers for only few weeks and to see them after the first course of treatment, however, the second brothers were followed for more than one year, and it was possible to achieve cure of the main autistic features.

The first two brothers (Figure-1) whom were first seen on the $25^{\text {th }}$ of July, 2019, aged ten and seven years respectively.

The older brother (Figure-1A) had severe autistic feature and had no eye contact and was not responding to name, and displayed abnormal behaviors with sitting in an abnormal attitude on the chair at the clinic. He had evidence of mental retardation as he had no bowel control, and was still unable to eat with spoon.

The younger brother had less severe condition, but he was also not responding to name, but he had some eye contact. He also had evidence of mental retardation as he was still unable to eat with spoon, but he was able control bowel. The younger brother was rather anxious at the clinic.

The two brothers were not saying any word, and were not responding to commands nor understanding speech. Both brothers received intramuscular cerebrolysin $5 \mathrm{ml}$ daily for 20 days plus oral trifluoperazine $1 \mathrm{mg}$ daily in the morning. Additionally, the older brother received oral risperidone $1 \mathrm{mg}$ at night, and the younger brother received oral citicoline $300 \mathrm{mg}$ daily in the morning.

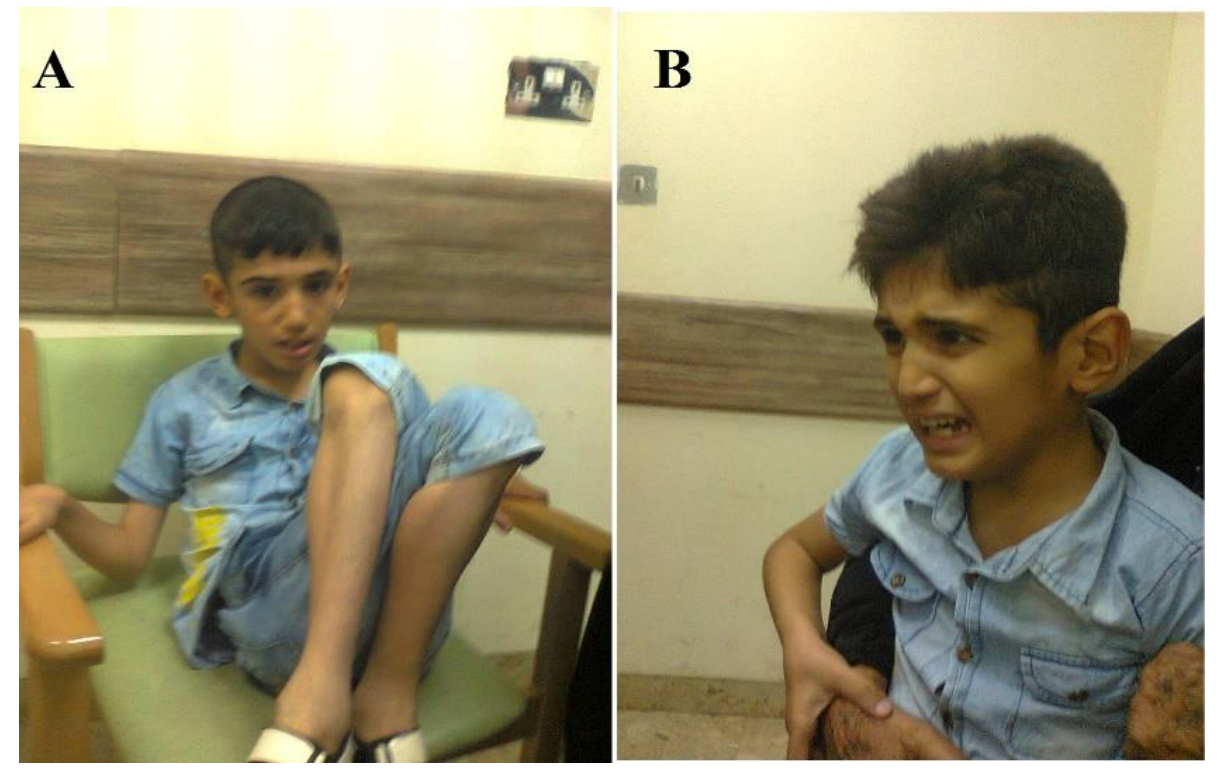

Figure 1: The first two brothers were first seen on the 25th of July, 2019

The second two brothers whom were first seen on the $22^{\text {nd }}$ of August, 2019, aged eleven and eight years respectively. The older brother had severe disorder with no eye contact and was not responding to name, and had displayed significant repetitive movements at the clinic (Figure-2). He was not saying any word, was still unable to control bowel nor was able to eat with a spoon.
The younger brother had less severe disease as he had some eye contact, but was not responding to name. He had poor speech development which started at the age of six years. He achieved bowel control late at the age of five years, and he was able to eat with a spoon. Table- 1 shows the treatments of the second two brothers. 

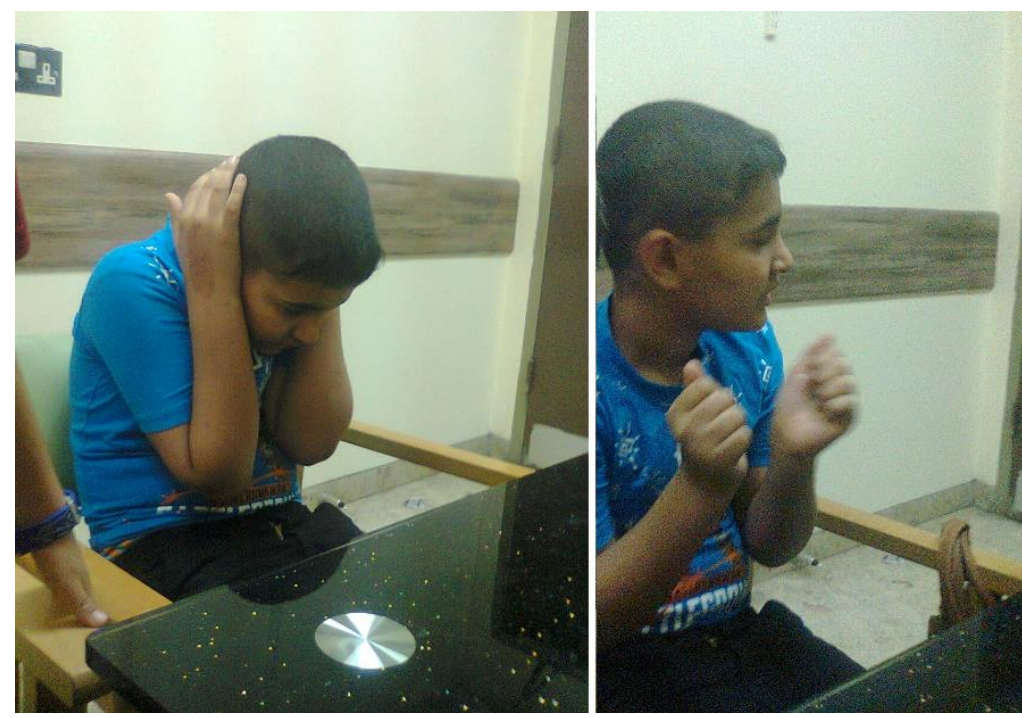

Figure-2: The older brother had severe disorder with no eye contact and was not responding to name, and had displayed significant repetitive movements at the clinic

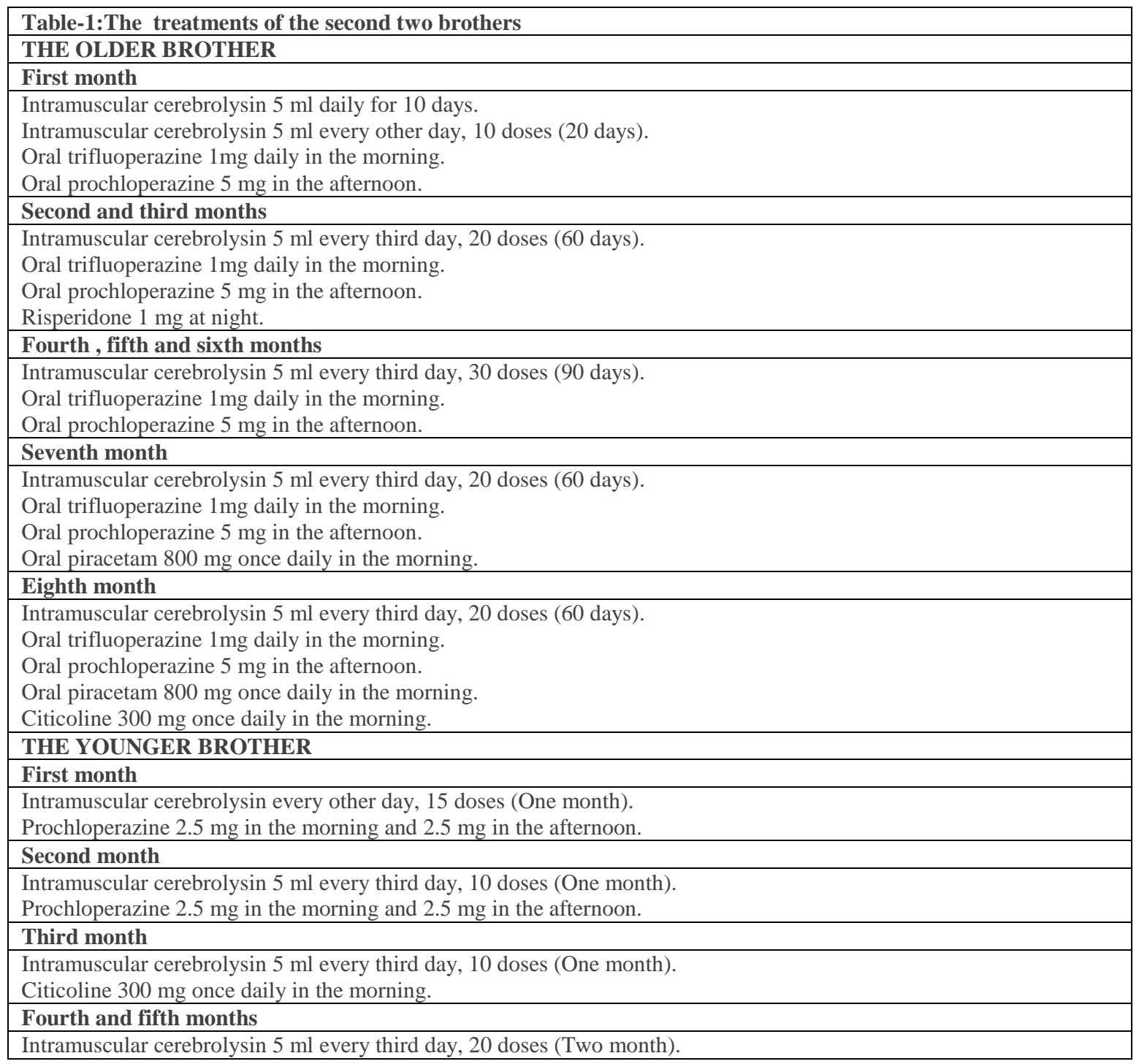




\section{Results}

After one short course, the first two brothers showed slight but noticeable improvement. The older brother experienced improvement in behavior and at the clinic he sat on the chair in a normal manner (Figure-3), and showed some anxiety instead of the indifference observed at the clinic before treatment. The younger brother showed some reduction in autistic features as he developed rather an acceptable eye contact. However, the two brothers were still not responding to name and didn't say any word.

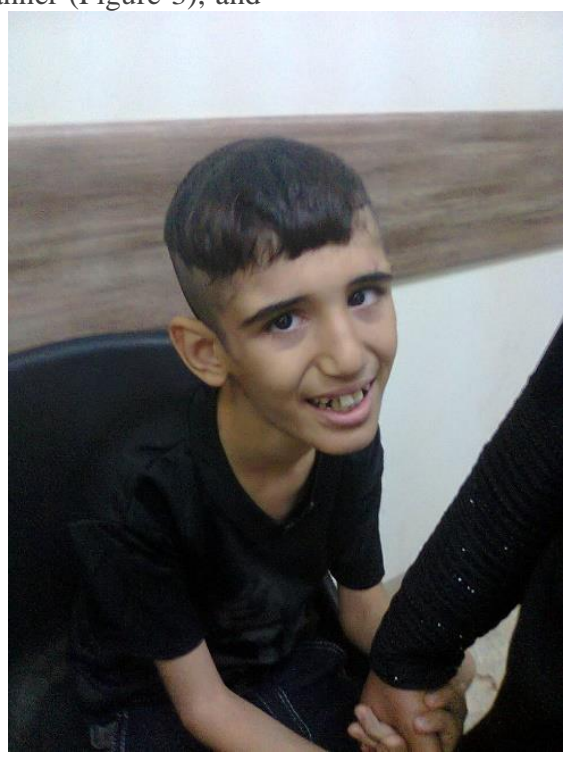

Figure 3: The older brother experienced improvement in behavior and at the clinic he sat on the chair in a normal manner, and showed some anxiety instead of the indifference before treatment

After the treatments in table-1, the second two brothers showed neither autistic features nor repetitive behaviors, and experienced significant improvements cognitive functions.

The older brother was not having autistic features or repetitive movements after eighth months of treatment, and was obeying commands and accepting shaking hands (Figure-4), but was still saying only few words, and was unable to answer when asked "What is your name". He also achieved bowel control and spoon feeding.

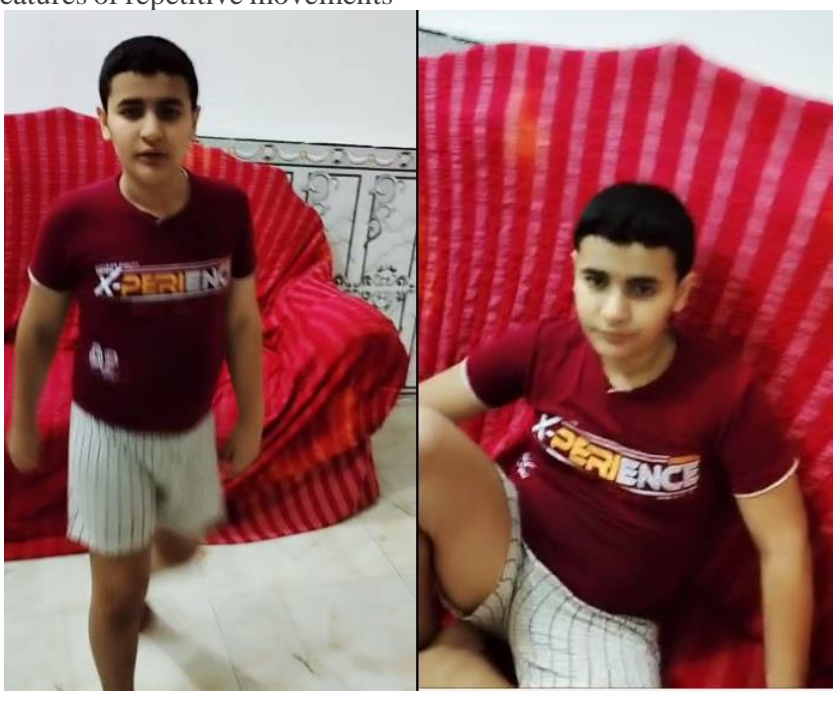

Figure 4: After eighth months of treatment, the older brother experienced significant improvements in cognitive functions, as he was understanding and responding to simple commands well. He sat when the mother asked him to sit

Figure-5 shows the younger brother after five month of treatment trying to copy a line, a circle, and a square. Thereafter, the younger brother joined primary school and was doing well apart from some behavioral problems especially running away from school and sometimes breaks things. 


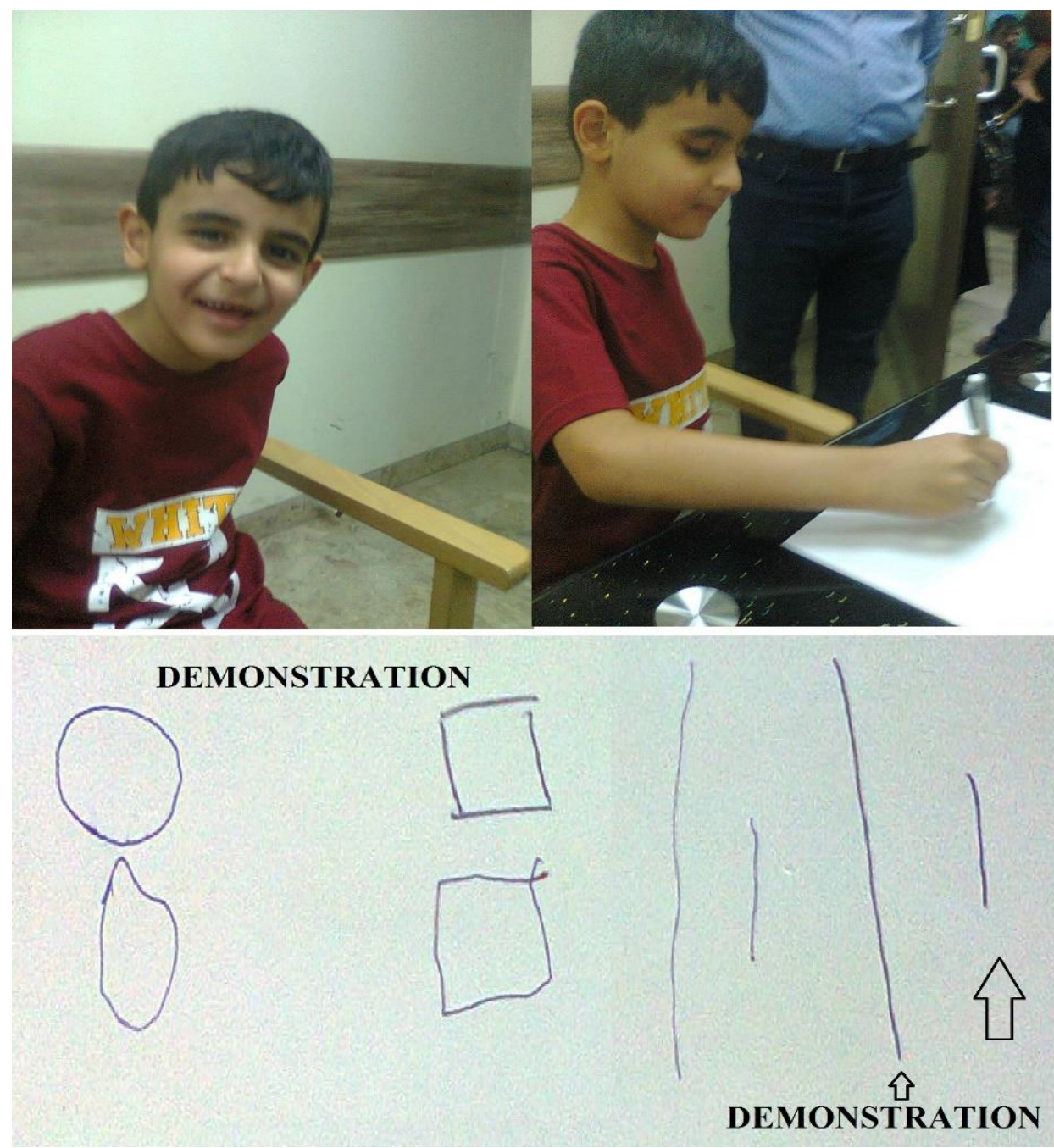

Figure 5: The younger brother after five month of treatment after disappearance of the autistic features. He was trying to copy a line, a circle, and a square

However, cure of autism at his age has never been expected to totally normalizes him, as he has already lost several years of learning, social adaptation, and maturation of personality and behavior.

\section{Discussion}

In this paper, cure of autism was achieved in two brothers with autosomal recessive autism treated with courses of intramuscular cerebrolysin which was used with other adjunctive therapies including neuroleptics (Trifluoperazine, prochloperazine, and risperidone), citicoline, and piracetam.

Cerebrolysin solution contains free amino acids (85\%) and $15 \%$ biologically active low molecular weight amino acids including neuropeptides (Brain-derived neurotrophic factor, glial cell line-derived neurotrophic factor, nerve growth factor, ciliary neurotrophic factor [14]. Cerebrolysin has been used safely with benefit in a variety of neuropsychiatric disorders including idiopathic mental retardation [15, 16], cerebral palsy [17, 18], myelomeningocele [19], pediatric juvenile spinal muscular atrophy [20, 21], pediatric Charcot Marie Tooth disease [22, $23]$, kernicterus [24, 25], agenesis of corpus callosum with colpocephaly $[26,27]$.

Citicoline, which has been increasingly grouped with the water soluble B vitamins, and is regarded as a form of the essential nutrient choline. It has been increasingly used with noticeable benefits in the treatment of several pediatric neuro-psychiatric disorders including, pervasive developmental disorders including Rett syndrome, and kernicterus [28-29].

Piracetam beneficial effects on impaired cerebral functions include improving neuronal and cognitive functions, increasing cerebral blood flow and oxygen consumption, improving neurotransmitters function and brain neurotransmission. Piracetam is not associated with important side effect nor has acute toxicity at the therapeutic doses. Piracetam has been used with important benefits in the treatment of cerebral palsy and other childhood neuro-psychiatric disorders [30, 31].

The occurrence of autosomal recessive cases of autism has been reported as early as 1985[32]. In 1988, Smalley et al. emphasized the genetic heterogeneity of autism disorders and their association with mental retardation, and the occurrence of autosomal recessive inheritance [33].

\section{Conclusion}

In this paper, cure of autism has been achieved in two boys with autosomal recessive disorder. However, cure of autism in older children has never been expected to totally normalizes them, as the patients have already lost several years of learning, social adaptation, and maturation of personality and behavior. 


\section{Acknowledgement}

The author is grateful for the parents for willing accepting publishing the photos of their children.

\section{Conflict of interest: None.}

\section{References}

1. Al-Mosawi AJ. (2019). Pervasive developmental disorders in Iraqi Children. Journal of Psychiatry Research Reviews \& Reports. 1(1):1-8.

2. Al-Mosawi AJ. (2019). The pattern of pervasive developmental disorders in Iraqi children. Saarbrücken.

3. Al-Mosawi AJ. (2018). Pediatric psychiatry: An accredited training course. $1^{\text {st }}$ ed., Saarbrücken.

4. Al-Mosawi AJ. (2020). Case studies in pediatric psychiatry: An approach to deep learning. $1^{\text {st }}$ ed., Saarbrücken.

5. Al-Mosawi AJ. (2018). A new therapeutic approach for pervasive developmental disorders. Saarbrücken.

6. Al-Mosawi AJ. (2018). Asperger syndrome and regressive autism. $1^{\text {st }}$ ed., Saarbrücken.

7. Al-Mosawi AJ. (2019). New therapies for Rett syndrome. J Bio Innov. 8(3):301-307.

8. Al-Mosawi AJ. (2019). Childhood dementia: Heller syndrome. Saarbrücken; LAP.

9. Al-Mosawi AJ. (2019). Heller syndrome in two Iraqi children. Clinical Research and Trials. 5:1-3.

10. Al-Mosawi AJ. (2021). An introduction to child psychiatry: A training course. Scholars' Press.

11. Al-Mosawi AJ. (2019). The use of cerebrolysin and citicoline in autism and Asperger syndrome. Journal of Bio Innovation. 8(1):99-108.

12. Al-Mosawi AJ. (2020). Our experience with childhood pervasive developmental disorders (Autism and Asperger Syndrome): Cure is Possible. EC Clinical and Medical Case Reports. 3(4): 01-08.

13. Al-Mosawi AJ. (2020). Cure of Autistic Disorders: Mission Impossible is Possible in an Illustrated Pioneering Experience. Archives of Health Science. 4(1):1-26.

14. Al-Mosawi AJ. (2020). Clinical uses of Cerebrolysin in Pediatric Neuropsychiatry. Science World Journal of Pharmaceutical Sciences. 1(1):1-4.

15. Al-Mosawi AJ. (2020). A Unique experience with mental and developmental retardation: Innovative Medical therapies for idiopathic mental retardation. EC Clinical and Medical Case Reports. 3(5):42-54.

16. Al-Mosawi AJ. (2020). Treatment of A Boy with Idiopathic Mental Retardation: From Uneducable to Educable. Progressing Aspects in Pediatrics and Neonatology. 2(5):197202.
17. Al-Mosawi AJ. (2019). New Therapies for the treatment of spastic cerebral palsy. Medical Journal of Clinical Trials \& Case Studies. 3(2):1-9.

18. Al-Mosawi AJ. (2020). New Therapies for the treatment of ataxic cerebral palsy caused by kernicterus. EC Clinical and Medical Case Reports. 3(4):26-31.

19. Al-Mosawi AJ. (2019). New medical therapies for the treatment of myelomeningocele. Surgical Medicine Open Access Journal. 2(4):1-4.

20. Al-Mosawi AJ. (2018). A novel therapy for pediatric juvenile spinal muscular atrophy. $1^{\text {st }}$ ed. Saarbrücken; LAP Lambert Academic Publishing.

21. Al-Mosawi AJ. (2020). The use of cerebrolysin in pediatric Wohlfart Kugelberg Welander syndrome. MOJ Clinical \& Medical Case Reports. 10(1):20-23.

22. Al-Mosawi AJ. (2018). A novel therapy for pediatric Charcot Marie Tooth disease. $1^{\text {st }}$ ed., Saarbrücken; LAP Lambert Academic Publishing.

23. Al-Mosawi AJ. (2020). The use of Cerebrolysin in Pediatric Charcot Marie Tooth Disease. Journal of neurological research and therapy. 3(2):17-21.

24. Al-Mosawi AJ. (2019). The novel use of cerebrolysin and citicoline in the treatment of kernicterus. Online Journal of Neurology and Brain Disorders. 3(1):208-212.

25. Al-Mosawi AJ. (2019). The Use of Intramuscular Cerebrolysin and Citicoline in the Treatment of Kernicterus. SunKrist Journal of Neonatology and Pediatrics. 1(1):1-5.

26. Al-Mosawi AJ. (2019). Agenesis of corpus callosum with colpocephaly: A novel therapy. $1^{\text {st }}$ ed., Saarbrücken; LAP Lambert Academic Publishing.

27. Al-Mosawi AJ. (2020). The use of piracetam and cerebrolysin in the treatment of agenesis of corpus callosum with colpocephaly. EC clinical and medical case reports. 3(1):1-5.

28. Al-Mosawi AJ. (2019). Citicoline research progress. $1^{\text {st }}$ ed., Saarbrücken; LAP Lambert Academic Publishing.

29. Al-Mosawi AJ. (2019). The Use of Citicoline in Pediatric Neurology and Pediatric Psychiatry. Austin Pediatrics. 6(1):1071-1072.

30. Al-Mosawi AJ. (2020). Recent Uses of Piracetam in Pediatric Neurology. SunKrist Neurology, Neurosurgery and Stroke Journal. 2(1):1002(1-5).

31. Al-Mosawi AJ. (2020). Goldberg Shprintzen Syndrome: A Novel Therapeutic Approach. EC clinical and medical case reports. 3(11): 115-123.

32. Ritvo ER, Spence MA, Freeman BJ, Mason-Brothers A, Mo A, Marazita ML. (1985). Evidence for autosomal recessive inheritance in 46 families with multiple incidences of autism. Am J Psychiatry. 142(2):187-192.

33. Smalley SL, Asarnow RF, Spence MA. (1988). Autism and genetics. A decade of research. Arch Gen Psychiatry. 45(10):953-961. 